\title{
İdollerin Frig Kültüründeki Kimliğine Dair Bir Analiz
}

\author{
An Analysis of the Identity of Idols in Phrygian Culture
}

\section{Rahşan Tamsü Polat* ${ }^{*}$}

\section{Öz}

Grekçede -eidolon, Latincede -idolum kelimesinden türetilmiş olan, imge, görüntü anlamına gelen idoller, Prehistorik döneme kadar geri giden, farklı dönemlerde farklı kültürlerde kendine yer bulmuş, tanrı ya da tanrıçayı temsil ettiği düşünülen, genellikle baş ile gövdelerin, bazen de boyun, kol, yüz ve diğer uzuvların da gösterildiği, şematize edilmiş soyut tasvirlerdir. Frigya Bölgesi sınırlarında, Frig Dönemi'ne tarihlenen tabakalarda tespit edilen yuvarlak bir baş ve dörtgen gövdeden oluşan bir grup tasvir de idol olarak adlandırılmaktadır. İdol betimlerinin, Frig kült anıtları ve Eski Frigçe yazıtlar ile Frig dininde ön plana çıkan Ana Tanrıça Matar’ın soyut betimleri olduğu, pek çok araştırmacı tarafından kabul edilmektedir. Fakat belirtilen coğrafyada tekli idollerin dışında, tek gövdeyi paylaşan yan yana yapılmış iki baş ya da ayrı olarak, yan yana baş ve gövdelerden oluşan idollerin de bulunması, bu başların hangi tanrı ya da tanrıçayı tasvir ettiğine dair bir soruyu beraberinde getirmektedir.

Bu makalede Frig dininde etkin bir biçimde tapınım gören ana tanrıçanın soyut betimlerinden olduğu düşünülen idollerin arkeolojik ve epigrafik buluntular yardımıyla Frig kültürünün öncülü ve ardılı olan kültürlerdeki yansımalarına değinilmiş, çift ve çoklu idollerin kimliğine dair sorulara cevaplar aranmıştır.

\section{Anahtar Kelimeler}

Frigya Bölgesi, Frig, İdol, Ana Tanrıça Matar, Paredros

\begin{abstract}
Derived from the Greek -eidolon and the Latin -idolum, idols, meaning image or visual, stretching back to the Prehistoric Period, are schematized abstract depictions that have found themselves a place within different cultures during different periods, are thought to depict a god or goddess, and generally show a head and body, sometimes with a neck, arms, face, and other organs. The group of portrayals with a round head and rectangular body found within the borders of Phrygia, in the strata dated to the Phrygian Period determined to be Phrygian, are known as idols. It has been accepted by many researchers that the idol depictions are abstract representations of the Mother Goddess, Matar, who takes center stage in the cultic monuments and Old Phrygian inscriptions of Phrygian religion. However, in addition to the single idols found in the aforementioned area, the presence of idols with two collateral heads on a single body or separate but collateral heads and bodies bring about the question of which god or goddess they represent. In this article, we will touch on the reflections of the idols thought to be abstract depictions of the actively worshipped Phrygian mother goddess in the cultures previous and after Phrygia with archeologic and epigraphic finds and attempt to determine the identity of double and multiple idols.
\end{abstract}

\section{Keywords}

Phrygian Region, Phrygian, Idol, Mother Goddess Matar, Paredros

* Sorumlu Yazar: Rahşan Tamsü Polat (Doç. Dr.), Anadolu Üniversitesi, Edebiyat Fakültesi, Arkeoloji Bölümü, Eskişehir, Türkiye. E-posta: rahsantp@anadolu.edu.tr ORCID: 0000-0002-5002-9560

Atıf: Tamsu Polat, Rahsan. “idollerin Frig Kültüründeki Kimliğine Dair Bir Analiz.” Art-Sanat, 17(2022): 451-473. https://doi.org/10.26650/artsanat.2022.17.930968 


\section{Extended Summary}

The idols thought to usually represent a god or goddess, identified as schematic and abstract depictions, and seen since the Prehistoric Period are generally schematized representations of a head and body, sometimes with a neck, arms, face, and other organs. Idol-type depictions found their place in the important powerhouse of the Iron Age, Phrygia. Phrygian idols generally consist of a round head and rectangular body. This group of idols consists of those made of stone or bone in a semi-iconic shape, those that are found on rocky outcrops, rocky surfaces, and in relief on the bedrock behind the steps of some altars, and those carved into steles.

The small number of Old Phrygian cultic inscriptions regarding the culture and cultic practices of Phrygia that survived to today through Greek literary texts from a limited source of information. In this case, our primary source of evidence of their culture is the archeologic artefacts found in cultic centers. Interpretations of these finds show that the Phrygians, who probably believed in many gods both male and female, adopted a deeply rooted, millennia-old, Anatolian belief in the Mother Goddess in their new home-centered in Central Anatolia and that they worshipped the goddess that they named "Matar" by building cultic monuments consisting of altars, niches, and facades in the rocky areas of valleys. The fact that the goddess, her name found in the Old Phrygian inscriptions on a group of rock facades, was the focus of worship in the Phrygian religion is evidenced in the anthropomorphic reliefs found on the steles. In addition to the anthropomorphic depictions of the goddess, a group of figures known as idols with round heads and rectangular bodies found within the borders of the Phrygian Region is worthy of note. In addition to these generally single idols, double idols are seen in the rocky outcroppings of the region, behind the steps of a group of altars, and on steles, and newly discovered triple idols are found in Midas Fortress, on a rock in Köhnüş Valley, and within the borders of Nakoleia (Seyitgazi). While the single idols are accepted by a group of researchers as "abstract depictions" of the goddess Matar, whose name is mentioned in Old Phrygian inscriptions, if we also accept that one of the heads on the samples with more than one collateral head again represents the goddess Matar, we are left with the important question of who the other head or heads depict. Some researchers note that in the double idols, one of the heads represents the goddess, the other a now unknown one of Matar's paredros. Many experts on the subject lean towards the idea that the figure next to the Mother Goddess is a "Father God", based on the religious iconography of earlier and contemporary cultures, and have made some inferences and suggestions as to the identity of this Father God. It is known that in Greek mythology, Attis is the goddess's lover. Using this information and the fact that the word -ata or -atas, seen on a few monuments, could be the basis of the -Attis found in sources from the Greek and Roman Periods, they interpret the figure as the goddess's lover in Greek mythology, Attis. However, no epigraphic or 
archeologic proof of the connection between the Phrygian -ata and the God Attis has yet been found.

One of the figures accompanying the goddess is thought to be the Phrygian King Midas, a part of the cult of Cybele. The foundation of this idea is the monumental-sized Midas Monument found in Yaz1lıkaya/Midas which features the name "Midai" together with the words lavagetas, -vanaks, thusly interpreted as an offering to Midas. The inclusion of the name "Midai" on the monument, is believed to allude to the fact that this person played a role like Attis in the goddess's cult.

The epigraphic research carried out in the Phrygian Region shows that many local gods and cults came about after the Hellenization of Anatolia's very old, local cults in addition to the fact that although the names of Greek gods are frequently used in inscriptions, the epithets seen alongside these names usually allude to local gods. In addition, epigraphic and iconographic materials in the region show many offerings with different epithets to Zeus during the Hellenistic and Roman Periods. The people in the rural areas of northwestern Phrygia in particular, presented many offerings to the god of weather and fertility, Zeus, but with different ancillary names. In Ancient

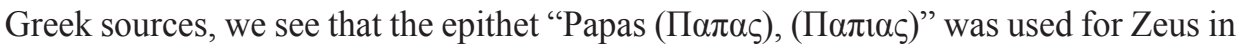
Bithynia and Papas or Zeus Papas was featured in the Greek inscriptions in Phrygian Highlands. Meaning "Father Zeus", this epithet is known to have also been used for Attis. In addition, the word "Baba" appears in a few Old Phrygian inscriptions and the meaning of this word, just like the way "Matar" was used to mean "mother", is noted as meaning 'father'. Another word found on these inscriptions is -ata. While the word " $a t a$ " is an Anatolian or Hittite term and the word -atta denoted Father or Father God, Brixhe and Drew Bear suggest that it is related to the Papas referred to in epigraphic and literary sources and that it is the name of a god. Therefore, they indicate that the superior Phrygian male god -ata, is "Father". After the Hellenization of the Phrygian Region, -ata generally became synchronized with Zeus, but in some regions, the Greek word "Papas (father)" was used. Such a large amount of documentation of Zeus can be explained by the presence of a belief in a strong, patriarchal father god of the land whose roots date back to very early periods in Phrygia. Lastly, based on epigraphic data and analyses of that data, it should not be incorrect to think that the double idols seen under the steps of altars or on steles represent the goddess and her paredros, or the Father God that accompanies her. 


\section{Giriş}

İnsan ve hayvan heykelcikleri, Üst Paleotik döneme kadar geri gitmekle birlikte ${ }^{1}$, küçük boyutlu yapılmış bu eserler genel olarak "figürin" adı altında isimlendirilmiştir. Üç boyutlu olarak yapılmış olan insan betimlemelerinde ise Neolitik dönemden itibaren yüz, göbek ve kalça gibi vücut detaylarının yapıldığı ve doğurganlığın vurgulandığı "Ana Tanrıça" olarak isimlendirilen "kadın teması" dikkati çekmektedir². Geç Neolitik döneme doğru ise heykelciklerin kol ve bacak kıvrımlarının azalarak bu uzuvların kazıma ve çizgilerle ifade edildiği yani daha az detay verilerek bir stilizasyona gidildiği görülür. Kalkolitik Çağ' da ise detayları azalan ve yassı bir form kazanan bu heykelcikler, Erken Tunç Çağı ile birlikte belirgin bir şekilde şematize edilerek "idol" adı verilen bir gruba evrilmiştir³.

İmge veya görüntü anlamına gelen, Grekçe -eidolon ${ }^{4}$, Latince idolon ${ }^{5}$ kelimelerinden türetilen idoller, çoğunlukla da tanrı ya da tanrıçaları temsil ettiği düşünülen, şematik ve soyut betimler olarak tanımlanmaktadır ${ }^{6}$. Figürin ve idol kavramları arasında keskin farklılıklar olmasa da Erken Tunç Çağı'ndaki biçimsel farklılığın belirginleşmeye başladığı görülmektedir. Artık Neolitik Çağ'ın abartılı vücut hatlarına sahip kadın betimlemelerinin yerini, çok daha şematize biçimde yapılmış, vücut detaylarının çoğunlukla kazıma çizgilerle verildiği, baş, boyun ve uzuvların soyut olarak işlendiği eserler almaya başlamıştır ${ }^{7}$. Bu tasvirlerin gövdelerindeki belirgin yassılaşma dikkati çekmektedir. İdollerde vurgulanan tema "soyutluktur". İnsanların zihinlerinde yer alan her şeye muktedir olan "tanrı/tanrıça" fikri bu soyut ve şematize edilmiş objelerde vücut bulmuştur. Erken Tunç Çağı'nın sonlarında idol betimler giderek azalmış, Demir Çağ'ın önemli bir gücü olan Frigler'de tekrar kendine yer buluştur. Frig idolleri genel olarak yuvarlak bir baş ve dörtgen bir gövdeden oluşmaktadır. Boyut olarak ise daha küçük boyuttaki Tunç Çağı figürlerinden farklı olarak ortalama yükseklikleri 0,50-1,00 m, genişlikleri 30-60 cm arasında değişmektedir. İdoller, taştan ve kemik-

1 Collin Renfrew ve Paul Bahn, Arkeoloji; Kuramlar, Yöntemler ve Uygulama (İstanbul: Homer Kitabevi, 2017), 399.

2 Şengül Gündoğan Aydıngün, "Yerleşik Hayat Öncesi: Yaratan Beden” Tunç Çă̆l’nın Gizemli Kadınları (İstanbul: Yapı Kredi Yayınları, 2005), 11-28.

3 Gündoğan Aydıngün, "Yerleşik Hayat Öncesi: Yaratan Beden", 24-25.

4 Henry George Liddell ve Robert Scott, "Eidolon", A Greek-English Lexicon (New York: Oxford University Press, 1996), 483.

5 “İdolon”, Oxford Latin Dictionary, ed. G. M. Lee (London: Oxford University Press, 1968), 820.

6 Gülsün Umurtak, “İdol”, Eczacıbaşı Sanat Ansiklopedisi, c. 2 (İstanbul: Yapı Endüstri Merkezi Yayınları, 1997), 834.

7 Gündoğan Aydıngün, "Yerleşik Hayat Öncesi: Yaratan Beden”, 31. 
ten yapılan yarı-ikonik olanlar ${ }^{8}$, kayalık alanlarda, kaya yüzeyine ${ }^{9}$ ve basamaklı kaya altarlarının bir kısmında, basamakların gerisindeki ana kaya yüzeyine kabartma olarak yapılanlar ${ }^{10}$ ile stel biçimli taş bloklar üzerine kazıma biçiminde yapılanlardan oluşurlar $^{11}$.

\section{Frig'lerde Ana Tanrıça Matar'ın Yansımaları}

Anadolu, MÖ 2. binyılın sonlarında, güneydoğu Avrupa' dan gelen birçok topluluğa ev sahipliği yapmıştır. Anadolu’ya gelen bu göç topluluklarından biri Makedonia ve

8 Gordion, Boğazköy, Kerkenes Dağ, Ovaören/Yassıhöyük’te yarı-ikonik idoller bulunmuştur. Gordion'daki örnekler için bk. Rodney S. Young, "Gordion-1950," University Museum Bulletin 16/1 (1951), 2-3, pl. VII, fig. 2; Keith DeVries, "The Gordion Excavation Seasons of 1969-1973 and Subsequent Research”, American Journal of Aarchaeology 94 (1990), 398, fig. 36; Lynn E. Roller, In Search of God the Mother. The Cult of Anatolian Cybele (London: Berkeley Los Angeles, 1999), 78, fig. 15; Boğazköy'deki örnek için bk. Kurt Bittel, "Phrygisches Kultbild aus Bogazköy”, Antike Plastik II (1963), fig. 2; Rainer Michael Boehmer, Die Kleinfunde von Boğazköy: Aus den Grabungskampagnen, 1931-1939 und 1952-1969, Wissenscaftliche Veröffentlichung der Deutschen Orient-Gesellschaft 87, Boğazköy-Hattuša 7 (Berlin: Mann, 1972), no: 2144 A, 2147, 2148, 2160; Kerkenes Dağ’daki örnekler için bk. Geoffrey Summers ve Françoise Summers, “Kerkenes Dağı Projesi 2003," Kazı Sonuçları Toplantısı 26/1 (2005), 104, fig. 8; Geoffrey D. Summers ve Françoise Summers, "Kerkenes 2009," Kazı Sonuçları Toplantısı 32/1 (2011), 386, fig. 7a-b; Geoffrey D. Summers ve Françoise Summers, “Kerkenes Dağ,” Frigler, Midas'ın Ülkesinde, Anitların Gölgesinde, ed. Taciser Tüfekçi Sivas ve Hakan Sivas (İstanbul: Yapı Kredi Yayınları, 2012), 170-171, fig. 10; Geoffrey D. Summers, "Phrygians East of the Red River: Phrygianisation, Migration and Desertion," Anatolian Studies 68 (2018), 104, fig.7; Ovaören/Yassıhöyük örneği için bk. Atakan Akçay, “Ovaören-Yassıhöyük'den Bir Yarı İkonik İdol," Arkeoloji ve Sanat 149 (2015), 50, res. 5.

9 Dağlık Frigya'da; Keskaya yerleşiminde Yazılıkaya Midas Kale'de, Yazılıkaya/Midas Vadisi'nin bitiminde Köhnüş Vadisi'nde, Karababa Vadisi'nde Fındık Asarkale'de görülür. Keskaya yerleşimindeki idol örneği için bk. Caroline Henriette Emilie Haspels, The Highlands of Phrygia. Sites and Monuments. 2 vols. (Princeton: The University Press, 1971), 98; Friederike Naumann, Die Ikonographie der Kybele in der Phrygischen und der Griechischen Kunst. Istanbuler Mitteilungen, Suppl. 28, Tübingen: Ernst Wasmuth, 1983), pl. 10 c; Midas Kale örnekleri için bk. Haspels, The Highlands of Phrygia. Sites and Monuments, 94-95, fig. 25-26, 36; Taciser Tüfekçi Sivas, Eskişehir-Afyonkarahisar-Kütahya İl Sinırları Iç̧indeki Phryg Kaya Anıtları (Eskişehir: Anadolu Üniversitesi Yayınları, 1999), no. A 17; Yazılıkaya/Midas Vadisi'nin bitimindeki örnek için bk. Yusuf Polat, "Yazılıkaya/Midas Vadisi Araştırmalarında Bulunan Bir Kaya İdolü," Colloquium Anatolicum 18 (2019), 143-144, fig. 3-4; Köhnüş Vadisindeki örnekler için bk. Tüfekçi Sivas, Eskişehir-Afyonkarahisar-Kütahya Il Sinırları İçindeki Phryg Kaya Anıtları, 170; Susanne Berndt Ersöz, Phrygian Rock-Cut Shrines. Structure, Function, and Cult Practise (Leiden-Boston: Brill, 2006), cat. no. 49, fig. 8, 65; Karababa Vadisindeki örnek için bk. Haspels The Highlands of Phrygia. Sites and Monuments, 59, 98; Naumann, Die Ikonographie der Kybele in der phrygischen und der griechischen Kunst, 97; Fındık Asarkale'deki örnekler için Taciser Sivas, "Eskişehir-Kütahya-Afyonkarahisar İlleri 2001 Yılı Yüzey Araştırması," Araştırma Sonuçları Toplantısı 20/2 (2003), 288; Taciser Tüfekçi Sivas ve Hakan Sivas, "Eskişehir- Kütahya-Afyon İlleri Yüzey Araştırması Arkeolojik Envanter Raporu,” Tüba-Kültür Envanteri Dergisi 1 (2003), 9, lev. 11, fig. 1-2.

10 Rahşan Tamsü, "Observations On The Phrygian Rock-Cut Altars," SOMA 2005 Proceedings of the IX Symposium on Mediterranean Archaeology, Chieti (Italy), 24-26 February 2005, Bar International Series, Vol.1739 (2008), 439-440, fig. 2-6; Rahşan Tamsü Polat, "Yeni Buluntular Işığında Phryg Kaya Altarları ve Bir Tipoloji Önerisi”, Anadolu Üniversitesi Sosyal Bilimler Dergisi 10/1 (2010), 207-208, res. 3-7.

11 Beli Köprü Yolu, Fahared Çeşme'deki örnek için bk. Hans Henning von der Osten, Explorations in Central Anatolia, Season of 1926 (Chicago: The University of Chicago, 1929), 59, fig. 90, pl. V; Naumann, Die Ikonographie der Kybele in der Phrygischen und der Griechischen Kunst, 94, taf. 9 vd.; Friedhelm Prayon, Phrygische Plastik: die Früheisenzeitlische Bildkunst Zentral-Anatoliens und ihre Beizehungen zu Griechenland und zum Alten Orient (Tübingen: E. Wesmut, 1987), pl. 15 c; Sincan Tatlar Köyü yakınında bulunan stel için bk. Mustafa Metin ve Mehmet Akalın, "Frigya'da Bulunan İkiz İdol," Anadolu Medeniyetleri Müzesi 2000 Yıllı̆̆ 15 (Ankara: Kültür Bakanlığg Anadolu Medeniyetleri Müzesi) 2001, 183-184, lev. 4. 
Thrakia'dan yaklaşık olarak 400 yıl süren göçler ile gelen ${ }^{12}$, "Bryges" olarak isimlendirilen ${ }^{13}$ ve Thrak kökenli bir topluluk olduğu büyük ölçüde kabul gören Frigler'dir ${ }^{14}$. Frigler MÖ 10. yüzyılın başlarında Gordion (Yassıhöyük) merkezli bir yönetim oluşturmuş, MÖ 9. yüzyıldan itibaren siyasi bir güç olarak geniş bir coğrafyada varlık göstermişlerdir ${ }^{15}$. Frigler'in hem yerleşim çeşitliliği hem de kült anıtları ile etkinlik gösterdikleri saha, günümüz sınırları ile Eskişehir, Afyonkarahisar ve Kütahya illeri arasında kalan ve Dağlık Frigya/Frigya Yaylası olarak adlandırılan kesimin güney ve güneydoğusunda, yükseltilerin aralarındaki derin vadilerdir. Bu vadilerde Frig döneminin yanı sıra özellikle Roma ve Bizans dönemlerine de tarihlenen kale tipi yerleşimler, ovalık alanlarda höyük tipi yerleşimler ile kayalık platoların yamaçlarında kaya mezarları bulunur. Vadilerde Frig kültürü ve dini mimarisinin ise en ünik örneklerini oluşturan kaya anıtlarının varlığı, bu vadilerin farklı dönemlerde farklı kültürlerin de varlık göstermesine karşın, Frig Vadileri olarak anılmasına neden olmuştur.

Frig kültürü ve kült uygulamalarına ilişkin az sayıdaki Yunan edebi metni ile günümüze az sayıda ulaşmış Eski Frigçe kült yazıtları, sınırlı bilgi kaynaklarındandır. $\mathrm{Bu}$ kültüre dair başlıca kanıtlar ise kült merkezlerinde bulunan arkeolojik buluntulardır ${ }^{16}$. Bu buluntuların yorumları, olasılıkla hem erkek hem de dişi çok sayıda tanrıya inanan Frigler'in ${ }^{17}$ Orta Anadolu merkezli yeni yurtlarında, binlerce yıldır Anadolu'da köklenen bir inanç olan "Ana Tanrıça" inancını benimsediklerini, "Matar" adını verdikleri tanrıçaya ${ }^{18}$, derin vadilerde, kayalık alanlarda fasad, altar ve nişlerden oluşan kült anıtlarını yaparak tapınımda bulunduklarını göstermektedir. Adına Eski Frigçe yazıtlarda rastlanan tanrıçanın ${ }^{19}$ bir grup kaya fasadında, Frig başkenti Gordion'da ve günümüz Ankara il sınırlarında bulunmuş olan stellerde, nişlerin ortasında, kabartma

12 Göç hareketleri için bk. Richard David Barnett, "Phrygia and The Peoples of Anatolia in The Iron Age," The Cambridge Ancient History II (1967), 3; Eckart Olshausen, "Phryges, Phrygia," Der Neue Pauly. Enzyklopädie der Antike, Band IX. (Stuttgart: Verlag J.B. Metzler, 1996), 965-967.

13 Herodotos, Herodot Tarihi, çev. Müntekim Ökmen (İstanbul: Remzi Kitabevi, 1991), VII, 73, 385; Strabon, Coğrafya Anadolu: Kitap: XII-XIII-XIV, çev: Adnan Pekman (İstanbul: Arkeoloji ve Sanat Yayınları, 1987), XII, 3, 20, 550, 405; Plinius Naturalis Historia, vol. 5, çev. H. Rackham (Loeb Classical Library) (London: New York 1947), V, 41, 145, 329.

14 Frigyalıların Thrakia'dan göç ettiğine karşı çıkan görüşler de bulunmaktadır. Robert Drews, "Myths of Midas and the Phrygian Migration from Europe," Klio 75 (1993), 11; Hermann Genz, "Thoughts on the Origin of the Iron Age Pottery Traditions in Central Anatolia," ed. Altan Çilingiroğlu ve Gareth Darbyshire, Anatolian Iron Ages 5, Proceedings of the Fifth Anatolian Iron Ages Colloquium Held at Van, 6-10 August 2001 (Ankara: British Institute at Ankara, 2005) 82. Frig göçlerine dair görüşlerin analizi için ayrıca bk. Emre Erdan, Frig Kültürü ve Uygarllğl, (İstanbul: Arkeoloji ve Sanat Yayınları, 2018), 167-188.

15 Günümüz sınırları ile Frigler Ankara ili ve çevresi, Kızılırmak Nehri’nin doğusunda Çorum, Tokat ve Kırşehir, kuzeyde Samsun, güneyde Niğde ve Konya, güneybatıda Burdur ve Elmalı Ovası batıda Eskişehir, Afyonkarahisar ve Kütahya, kuzeybatıda Bandırma'ya kadar olan bölgede etki alanlarını genişletmişlerdir. Tüfekçi Sivas, Eskişehir-Afyonkarahisar-Kütahya İl Sinırları İçindeki Phryg Kaya Anıtları, 34.

16 Roller, "Frig Dini ve Kült Uygulamalar1," 202.

17 Lynn E. Roller, "Frig Dini ve Kült Uygulamaları,” Friglerin Gizemli Uygarlığ (İstanbul: Yapı Kredi Yayınlar1 2007), 141.

18 Roller, In Search of God the Mother. The Cult of Anatolian Cybele, 66.

19 Claude Brixhe ve Michel Lejeune, Corpus des Inscriptions Paléo-phrygiennes. 2 vols. (Paris: Éditions Recherche sur les Civilisations, 1984) matar: M-01 c, M-01d I, M 01 d II, M-0le, W-01 b, W 03, W-06. 
olarak yapılmış insan suretindeki (antropomorfik) betimlemeleri tanrıçanın, Friglerin inancında tapınımın odağında olduğunu kanıtlamaktadır ${ }^{20}$. Matar, bu tasvirlerin hemen hemen hepsinde ayrıntılar dışında benzer ikonografik özellikler ile betimlenmiştir. Stellerde Tanrıça genel olarak alınlıklı, mimari bir çerçevenin içinde gösterilmiştir. Bu mimari çerçeve, ana tanrıçanın kutsal mekânının yani tapınağının stellere yansımasıdır ${ }^{21}$. Tanrıça hem kabartmalarda hem de serbest heykellerde, oldukça benzer bir betim şeması içerisinde, olgun bir kadın görünümünde ve bu toprakların yabancısı olmayan Anadolulu olgun bir "Ana”yı yansıtır şekilde betimlenmiştir. Genellikle başında yüksek bir polos, ayaklarına kadar uzanan elbise, omuzlarından aşağıya doğru sarkan örtü ile ayakta ve cepheden betimlenmiştir. Vücut durağandır; kollar gövdeye bitişik ve çoğunlukla dirsekten bükülmüştür. Çoğu örnekte tanrıça elinde yırtıcı kuş ve kâse tutarken betimlenirken, bazen de Tanrıça'ya aslanlar eşlik etmektedir.

Boğazköy’de, Büyükkale'nin doğu kapısının önünde niş içinde, in situ olarak bulunan tanrıça ile birlikte biri lyra ya da kithara, diğeri çifte flüt (aulos) çalan iki küçük erkek figürünün yer aldığı heykel grubu ise Tanrıçanın bilinen betim şeması dışındaki tekil bir örnektir²2. Tanrıçanın, bir grup kaya fasadının ve stellerin ortasındaki niş içerisindeki kabartma tasvirleri ile Eski Frigçe yazıtlarda adına rastlanılması, Frig kültür sahası içerisinde tekil birkaç örneğin dışında ${ }^{23}$ insan suretinde betimlenmiş başka örneklerin henüz bulunmayışı, Tanrıçanın Frig dinindeki baskın rolünü ve etkinliğini yansitan somut arkeolojik kanıtlardır.

20 Bu betimlerin dışında, Tanrıça'nın az sayıda bulunmuş heykelleri de vardır. Dağlık Frigya Bölgesi'nde Yazılıkaya/Midas Kale'deki örnekler için bk. Caroline Henriette Emilie Haspels, Phrygie, Exploration Archeologique III, La Cite de Midas, Ceramique et Trouvailles Diverses (Paris: E. De Boccard, 1951), 114, pl. 47 a-b; Prayon, Phrygische Plastik: die Früheisenzeitlische Bildkunst Zentral-Anatoliens und ihre Beizehungen $z u$ Griechenland und zum Alten Orient no: 1, pl.1 a-f; Gordion'daki örnekler için bk. Rodney S. Young, "Doodling at Gordion," Archeology 22 (1968), 270-273; Naumann, Die Ikonographie der Kybele in der Phrygischen und der Griechischen Kunst, 151; Prayon, Phrygische Plastik: die Früheisenzeitlische Bildkunst Zentral-Anatoliens und ihre Beizehungen zu Griechenland und zum Alten Orient, 201, cat. no. 5, pl. 2 a-b; Roller, In Search of God the Mother. The Cult of Anatolian Cybele, 20, I, cat. no. 6, pl. 2c-e; Ankara ve yakınlarındaki örnekler için bk. Bittel, "Phrygisches Kultbild aus Bogazköy," pl. II. c-d; Prayon, Phrygische Plastik: die Früheisenzeitlische Bildkunst Zentral-Anatoliens und ihre Beizehungen zu Griechenland und zum Alten Orient, 201, cat. no.5, pl. 2 a-b; Roller, In Search of God the Mother. The Cult of Anatolian Cybele, 201, cat. no. 5, pl. 2a-b; Roller, In Search of God the Mother. The Cult of Anatolian Cybele, 73; Boğazköy'de Frig yerleşim tabakasındaki örnek için bk. Kurt Bittel, "Untersuchungen auf Büyükkale," Mitteilungen der Deutschen Orient-Gesellschaft 91, (1958), 57-59, Bittel, "Phrygisches Kultbild aus Bogazköy", 7-21, pl. II c-d; Prayon, Phrygische Plastik: die Früheisenzeitlische Bildkunst Zentral-Anatoliens und ihre Beizehungen $z u$ Griechenland und zum Alten Orient, 201, cat. no. 5, pl. 2 a-b; Roller, In Search of God the Mother. The Cult of Anatolian Cybele, 72, fig. 10.

21 Ekrem Akurgal, Die Kunst Anatoliens von Homer bis Alexander (Berlin: Gruyter, 1961), fig. 22; Roller In Search of God the Mother. The Cult of Anatolian Cybele, fig. 9; Fahri Işık, Uygarlık Anadolu'da Doğdu (İstanbul: Ege Yayınları 2012), 277.

22 Bittel, "Untersuchungen auf Büyükkale", 57-59; Bittel, "Phrygisches Kultbild aus Boğazköy," 7-9, pl. 1-8; Prayon, Phrygische Plastik: die Früheisenzeitlische Bildkunst Zentral-Anatoliens und ihre Beizehungen zu Griechenland und zum Alten Orient, 201, cat. no.5, pl. 2a-b; Roller, In Search of God the Mother. The Cult of Anatolian Cybele, 72, fig. 10.

23 Erkek ve kadın kült figürleri sınırlı sayıdadır. Gordion'da şehir kapısı önünde bulunan erkek başının Kerkenes (Petria)'de bulunan erkek heykeline benzer şekilde bir tanrıyı ya da kahramanlaştırılmış bir atayı temsil ettiği yorumu yapılmaktadır (Lynn E. Roller, "Frig Dini ve Kült Uygulamaları/Phrygian Religion and Cult Practise, ed. Taciser Tüfekçi Sivas ve Hakan Sivas (İstanbul: Yapı Kredi Yayınları, 2012), 221. 
İnsan suretinde betimlenmiş tanrıça tasvirlerinin dışında, Frigya Bölgesi sınırlarında bulunan yuvarlak bir baş ve dörtgen gövdeden oluşan, idol olarak adlandırılan bir grup tasvir de dikkati çekmektedir. Prehistorik döneme kadar geri giden ${ }^{24}$ Frig idolleri, taştan ve kemikten yarı-ikonik olarak yapılanlar, kayalık alanlarda, kaya yüzeyine ve basamaklı kaya altarlarının büyük bir kısmında, basamakların gerisindeki ana kayaya kabartma olarak yapılanlar ${ }^{25}$ ile stel üzerine kazıma şeklinde yapılanlardan oluşur (G. 1-G. 5). Frig yerleşim sahası içerisinde tespit edilen idollerin hemen hepsi oldukça yalın bir biçimde sadece yuvarlak bir baş ve dörtgen gövdeli betimlenmiş, bazı örneklerde ise idollerin boyun ve omuz detayları da belirtilmiştirir ${ }^{26}$.

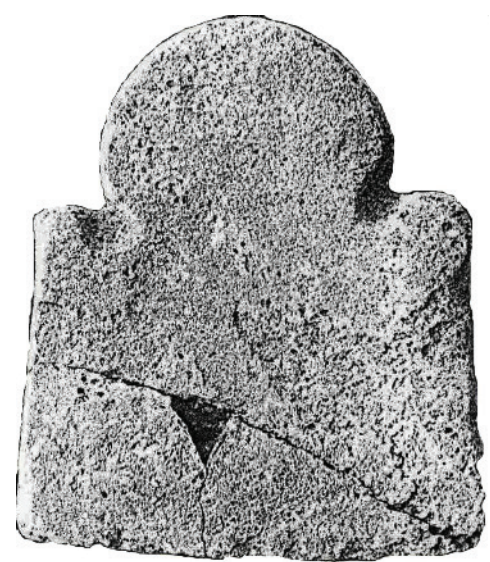

G. 1: Ankara ili, Polatlı ilçesi, Gordion (Yassıhöyük)'dan bulunan taş idol

(K. DeVries, "The Gordion Excavation Seasons of 1969-1973 and Subsequent Research”, 398, fig. 36).

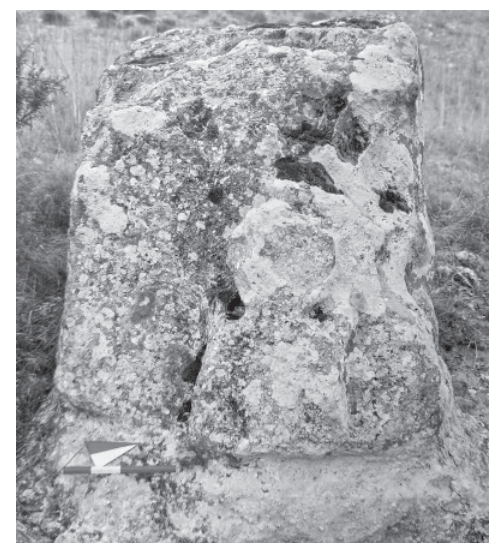

G. 2: Eskişehir ili, Karaalan Köyü, Keskaya yerleşimi. (R. Tamsü Polat, 2004)

24 Berndt Ersöz, Phrygian Rock-Cut Shrines. Structure, Function, and Cult Practise, 121.

25 Basamaklı altarların bazılarında idollerin çok daha stilize edilerek kavis şeklinde kabartmalara dönüştüğü görülür. Tamsü, “Observations On The Phrygian Rock-Cut Altars,” 439-441.

26 Boğazköy'den ele geçen birkaç örnekte ise göz ve ağız detaylarına yer verilmiştir. Naumann, Die Ikonographie der Kybele in der Phrygischen und der Griechischen Kunst, taf. 9a-d. 


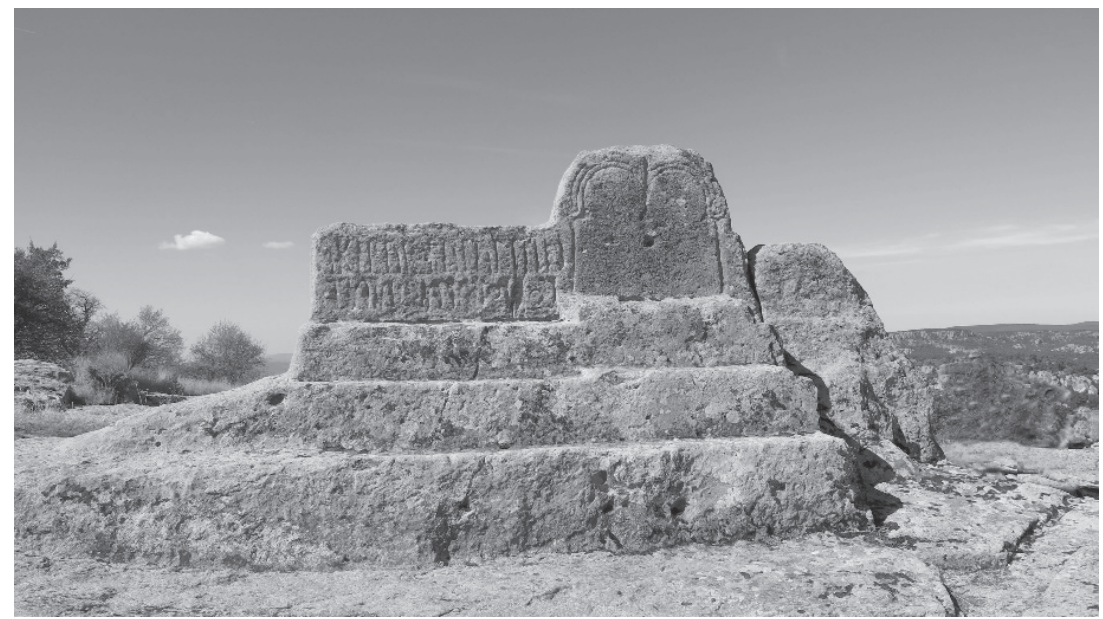

G. 3: Eskişehir ili, Yazılıkaya Köyü, Midas Kale Büyük Altar (R. Tamsü Polat, 2018)

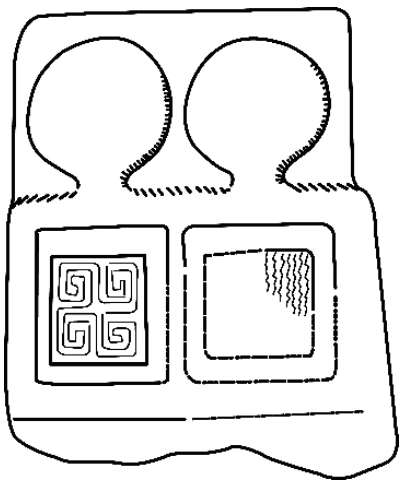

G. 4: Ankara ili, Fahared Çeşmesi'deki İkiz İdollü Kabartmanın çizimi

(F. Naumann, Die Ikonographie der Kybele in der Phrygischen und der Griechischen Kunst, taf. 9f).

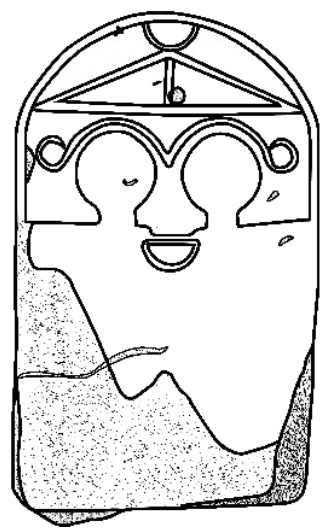

G. 5: Ankara ili, Sincan ilçesi, Tatlar Köyü’nde Bulunan İkiz İdollü Kabartmanın çizimi

(M. Metin ve M. Akalın, "Frigya'da Bulunan İkiz İdol”, lev. IV). 


\section{Çift/İkiz ve Çoklu İdoller: Paredrosa Dair İzler mi?}

Büyük bir kısmı tekli olarak yapılmış olan idollerin yanı sıra, kayalık alanlardakiler ile bir grup basamaklı altarın basamaklarının gerisinde yapılmış olanlar ile steller üzerindekilerin ikili (çift), Köhnüş Vadisi’nde, Midas Kale’de kaya üzerinde ve Nakoleia (Seyitgazi) sınırlarında yeni bulunmuş olan bir stelde ise üçlü idollere rastlanmıştır (G. 6, G. 7, G. 8).

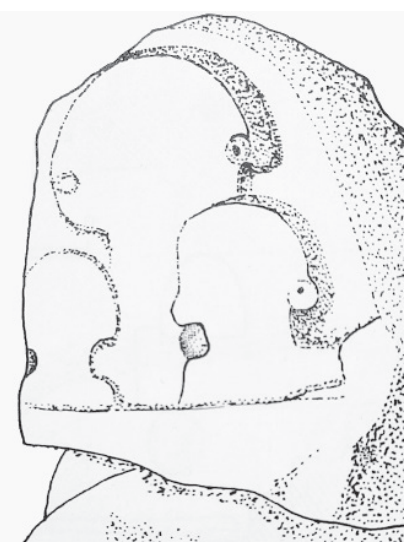

G. 6: Afyonkarahisar ili Köhnüş Vadisindeki üçlü idol (S. Berndt Ersöz, Phrygian Rock-Cut Shrines. Structure, Function, and Cult Practise, 362, fig. 66).

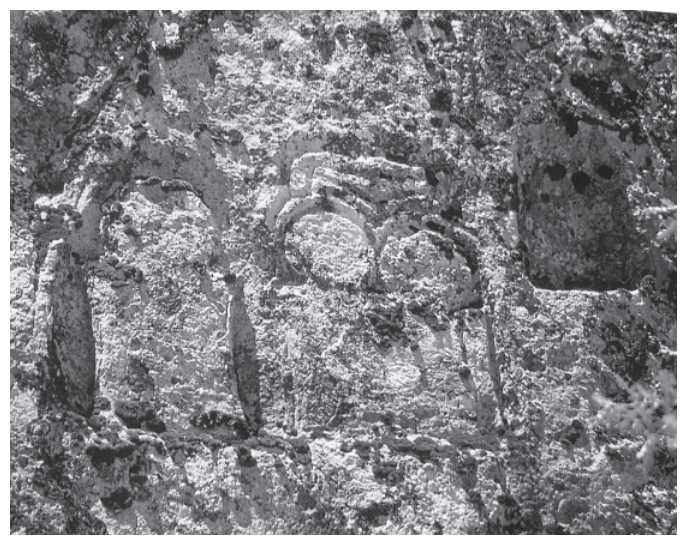

G. 7: Eskişehir ili, Yazılıkaya Köyü, Midas Kale'deki üçlü idol fotoğrafı. (R. Tamsü Polat, 2017) 


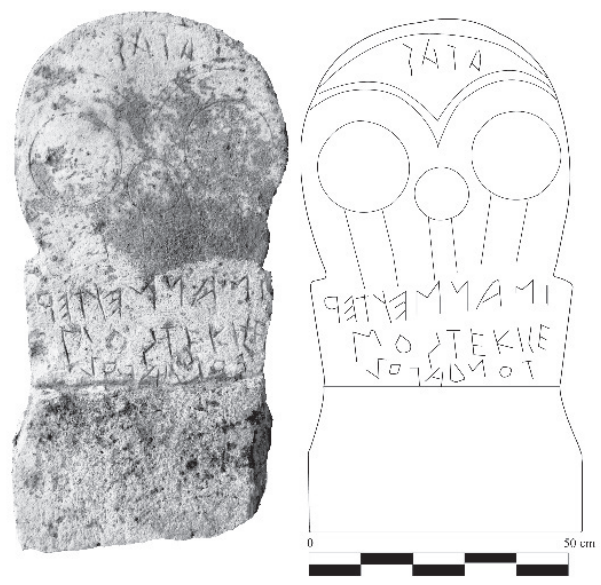

G. 8: Eskişehir ili, Seyitgazi ilçesi, Gümüşbel Köyü sınırlarında yer alan Eski Cami Höyük’ten bulunan idol şeklindeki stel (R. Tamsü Polat, Y. Polat, A. Lubotsky, "An Idol-shaped Stele with an Old Phrygian Inscription in the Territory of Nakoleia", 66-67, fig. 4-5).

Tek olarak yapılmış idollerin, Eski Frigçe yazıtlarda adı geçen Tanrıça Matar'ın "soyut tasvirleri” olduğu fikri bir grup araştırmacı tarafından kabul görmektedir ${ }^{27}$. Birden fazla başın yan yana yapıldı̆̆ı örneklerde başlardan birinin Tanrıça Matar'a ait olduğu kabul edilirse, diğer baş ya da başların kimi ya da kimleri betimlediği önemli bir sorudur ${ }^{28}$. Birden fazla başın yapıldığı idoller ile ilgili olarak, başların her ikisinin de tanrıçaya ait olduğu, yani tanrıçanın iki kere betimlenmiş olabileceği öne sürülmektedir ${ }^{29}$. Ayrıca çift idollerin yapılması ile tanrıçanın evrenin hâkimi, doğuran, koruyan ve kollayan Ana olarak farklı ilahi güçlerine işaret edildiğine de değinilmektedir $^{30}$. Yunan ve Roma Dönemi’nde Kybele'nin çift naiskoslarında Kybele'nin iki kere betimlendiği ve tanrıçanın doğasına özgü farklı objeler tuttuğu görülmektedir ${ }^{31}$. Fakat tanrıçanın Frig ikonografisindeki insan görünümündeki tasvirlerinde yan yana betimlenmiş bir örneği bilinmemektedir. Bununla birlikte çift olarak yapılmış idoller, birbirinden farklı olmamakla birlikte, aynı büyüklüktedir. Ayrıca çift idollerde cinsiyete ait işaret bulunmamaktadır.

Ankara ili, Sincan ilçesi sınırlarında yer alan Fahared Çeşme'de devşirme olarak kullanılan stel ${ }^{32}$ üzerinde kazıma şeklinde yapılmış idollerin gövdesinde, çizgisel üs-

27 Naumann, Die Ikonographie der Kybele in der Phrygischen und der Griechischen Kunst, 92-95; Roller, In Search of God the Mother. The Cult of Anatolian Cybele, 77-78.

28 Rahşan Tamsü Polat, Yusuf Polat ve Alexander Lubotsky, "An Idol-shaped Stele with an Old Phrygian Inscription in the Territory of Nakoleia", Gephyra 19 (2020), 51-53.

29 Naumann, Die Ikonographie der Kybele in der Phrygischen und der Griechischen Kunst, 99-100; Evgenia Vikela, "Bemerkungen zu Ikonographie und Bildtypologie der Meter-Kybelereliefs," Mitteilungen des Deutschen Archäologischen Instituts. Athenische Abteilung 116 (2001), 78.

30 Naumann, Die Ikonographie der Kybele in der Phrygischen und der Griechischen Kunst, 188-189.

31 Naumann, Die Ikonographie der Kybele in der Phrygischen und der Griechischen Kunst, nos. 336-354.

32 Metin ve Akalın, "Frigya'da Bulunan İkiz İdol," 183-184, pl. 4. 
lupta yapılan farklı bezeme detayları ${ }^{33}$, araştırmacılar tarafından cinsiyete işaret eden belirteçler olarak yorumlanmış, dikey çizgilerle bezeli gövdenin tanrıçanın elbise detayının kıvrımlarını, gövdesi swastika (çarkıfelek) bezemeli olanın ise bir tanrıyı betimlediği belirtilmiştir ${ }^{34}$. Tanrıçanın antropomorfik betimlerindeki elbise detaylarında görülen dikey çizgiler, pilelerin stilize edilmiş şekli olarak yorumlanabilir. O hâlde swastika motifi ile bezeli olan gövde, hangi tanrı ya da tanrıçaya aittir? Araştırmacıların bir kısmı yan yana yapılmış çift idollerde, başlardan birinin tanrıçayı, diğerinin de şimdilik bilmediğimiz Matar'ın paredrosunu yani ona eşlik eden tanrıları betimlediğini ileri sürmektedirler ${ }^{35}$.

Tanrıçanın paredrosuna ilişkin olarak, konu ile ilgili uzmanların çoğu, öncül ve çağdaş kültürlerdeki dinsel ikonografilerden yola çıkarak Ana Tanrıça'nın yanındaki figürün bir "baba tanrı" olma fikrini benimsemektedirler. Erkek ve kadın kült figürleri sınırlı sayıda olsa da Gordion'da bulunmakla birlikte, şehir kapısı önünde bulunan erkek başının, Kerkenes (Piteria)'de bulunan erkek heykeline benzer şekilde, bir tanrıyı ya da kahramanlaştırılmış bir atayı temsil ettiği şeklindeki yorumlar da "baba tanrı" kavramını destekler niteliktedir ${ }^{36}$. Bu durumda, baba tanrının kimliğine 1şık tutacak bilgilerin sorgulanması gerekecektir.

Friglerden önce bu coğrafyada bir İmparatorluk kurmuş olan Hititler'in ve Frigler' in çağdaşı olan Geç Hititler'in pantheonundaki ikonografik tasvirler ve yazılı metinler, her iki kültürde de hem tanrı hem de tanrıçaların var olduğunu kanıtlamaktadır. Bu görünümüyle pantheonları, Ana Tanrıça'nın neredeyse insan suretiyle tek başına varlık gösterdiği Frig dünyasından farklıdır. Fakat Hititlerde görülen kutsal dağ, tanrısal bir atribü olan yırtıcı kuş ve yeraltı su kaynakları ile pınarlarına önem verilmesi, Frig geleneği ile olan benzerliğe dikkat çekse de Frigler'in Hitit kült geleneğinin doğrudan mirasçısı olup olmadığını söylemek güçtür. İki kültürdeki ortak konular olan avlanma ve vahşi doğaya hükmedebilen bir tanrıçaya duyulan ilgi, Erken

33 Osten, Explorations in Central Anatolia, Season of 1926, 59, fig.90, pl. V; Naumann, Die Ikonographie der Kybele in der Phrygischen und der Griechischen Kunst. Istanbuler Mitteilungen, 94, pl. 9f; Prayon, Phrygische Plastik: die Früheisenzeitlische Bildkunst Zentral-Anatoliens und ihre Beizehungen zu Griechenland und zum Alten Orient, no. 47, taf. 15 c.

34 Kurt Bittel, Hattusha. The Captal of Hittites, (New York: Oxford University Press), 1970, 152; Machteld J. Mellink, "Midas-Stadt," Reallexikon der Assyriologie 8 (1993), 155.

35 Bittel, Hattusha. The Captal of Hittites, 152-153; Vassileva, "PAREDROI or Once Again on the Phrygian Rock Thrones," 265-267; Berndt Ersöz, Phrygian Rock-Cut Shrines. Structure, Function, and Cult Practise, 172; Machteld J. Mellink, "Temples and High Places in Phrygia in," Tempels and High Places in Biblical Times. Proceedings of the Colloquium in Honor of the Centennial of Hebrew Union College-Jewish Institute of Religion, Jerusalem, 14-16 March, 1977, ed. Avraham Brian (Jerusalem: Nelson Glueck School of Biblical Archaeology of Hebrew Union College-Jewish Institute of Religion, 1981), 98, 102; Sevim Buluç, "The Architectural Use of the Animal and Kybele Reliefs Found in Ankara and Its Vicinity," , Istanbuler Mitteilungen (1988), 20-21; Mellink, "Midas-Stadt," 155. "Paredros" kelimesinin anlamları için bk. Liddell ve Scott, "Paredros", A Greek-English Lexicon, 1332.

36 Roller, "Frig Dini ve Kült Uygulamaları", 221. 
Demir Çağ' da da bu inancın devam ettiğini düşündürmektedir ${ }^{37}$. Geç Hitit inancında görülen tanrıçanın imajı, Frig Ana Tanrıçası'nın görünümü ile benzerlik göstermektedir $^{38}$. Ancak hem Hitit hem de Geç Hitit kültüründe tek bir Ana Tanrıça'dan söz edilmemekle birlikte, Geç Hitit Tanrıçası bazen eşi ile betimlenmiştir ${ }^{39}$. Frigler'in öncülü ve çağdaşı olan kültürlerdeki tüm benzer yanlar göz önünde bulundurulduğunda, Frig Ana Tanrıçası'nın yanında, ona eşlik eden tanrı ya da tanrıların olabileceği düşünülmekte ve bazı ortak özelliklerden bir sonuca ulaşılmaya çalışılmaktadır ${ }^{40}$. O hâlde Frig tanrıçasının yanında ona eşlik eden tanrı ya da tanrılar kimlerdir? Bu konuda epigrafik kaynaklar dayanak gösterilerek birtakım ipuçları aranmaktadır: Yunan mitolojisinde tanrıçanın sevgilisinin Attis olduğu bilinmektedir. Bu bilgi ve birkaç anıt üzerinde görülen -ata kelimesi temel alınarak, -ata, atas'1n, Yunan ve Roma Dönemi kaynaklarında geçen -Attis olabileceği, böylece Yunan mitolojisinde tanrıçanın sevgilisi olarak görülen "Attis" olduğu yönünde bir yorum bulunmaktadır"11. Ancak Eski Frigçe -ata ile Tanrı Attis arasında önerilen bağlantıyı destekleyecek epigrafik ve arkeolojik kanıtlar şimdilik yoktur ${ }^{42}$. Ayrıca Attis'in, Frig döneminde bir tanrı olarak ortaya çıkmadı $\breve{g}_{1}^{43}$ Frigya'da Roma Dönemi öncesinde Attis adlı bir tanrıya tapınımı gösteren herhangi bir kanıtın şimdilik olmadığını söylemek gerekir ${ }^{44}$.

Tanrıçaya eşlik ettiği düşünülen figürlerden diğeri Kybele kültüne bağlı olan ${ }^{45}$ Frig Kralı Midas'tır ${ }^{46}$. Bu görüşün dayanağı ise Yazılıkaya/Midas yerleşiminde bulunan anıtsal ölçülerdeki Midas Anıtı'nda, Eski Frigçe "Midai” ismi ile birlikte geçen -lavagetas, -vanaks kelimeleridir. Anıt üzerinde bu kelimelerin okunması, anıtın Midas'a bir adak olarak yorumlanmasına neden olmuştur ${ }^{47}$. Anıtta "Midai" adının geçmesi nedeniyle, bu kişinin tanrıçanın kültünde Attis’e benzer bir rol oynadığının yani rahiplik

37 Roller, In Search of God the Mother. The Cult of Anatolian Cybele, 44.

38 Işık, Uygarlık Anadolu'da Doğdu, 279.

39 Roller, In Search of God the Mother. The Cult of Anatolian Cybele, 52-53.

40 Frig ikonografik betimlerinde, günümüze ulaşan bir erkek tanrı tasviri yer almamakla birlikte, yalnızca Boğazköy'de bulunan bir örnekte Matar'a küçük erkek müzisyenlerin eşlik ettiği görülür (Bittel, "Untersuchungen auf Büyükkale", 57-59; Bittel, "Phrygisches Kultbild aus Bogazköy," 7-9, pl. 1-8; Phrygische Plastik: die Früheisenzeitlische Bildkunst Zentral-Anatoliens und ihre Beizehungen zu Griechenland und zum Alten Orient, 201, cat. no.5, pl. 2a-b; Roller, In Search of God the Mother. The Cult of Anatolian Cybele, 72, fig. 10 .

41 Claude Brixhe ve Thomas Drew Bear, “Trois Nouvelles Inscriptions Paleo-Phrygiennes de Cepni," Kadmos 21, (1982), 83, 87.

42 Berndt Ersöz, Phrygian Rock-Cut Shrines. Structure, Function, and Cult Practise, 166, dpn. 185. Yalnızca Attis'e Pessinus'tan bir adak olduğu bilinmektedir ancak onun bir tanrı mı ya da bir yüksek rahip mi olduğu ise açık değildir.

43 Yunan dünyasında Attis'in betimi MÖ 4. yüzyılın ortalarından önce yoktur (Lynn E. Roller, “Attis on Greek Votive Monuments: Greek God or Phrygian?” Hesperia 63/2 (1994), 247; Birgitte Bøgh, “The Phrygian Background of Kybele," Numen 54/3 (2007), 320.

44 Roller, In Search of God the Mother. The Cult of Anatolian Cybele, 243.

45 Roller, In Search of God the Mother. The Cult of Anatolian Cybele, 246.

46 Maya Vassileva, "PAREDROI or Once Again on the Phrygian Rock Thrones", Thracia 11, 1995, 275.

47 Brixhe ve Lejeune, Corpus des Inscriptions Paléo-phrygiennes, M-01 a; Igor M. Diakonoff ve Vladimir Petrovich Neroznak, Phrygian, (New York: Caravan Books, 1985), 61-62, A 1-6. 
görevi ile tanrıçaya bağlı bir hükümdar olduğunun ima edildiği düşünülür ${ }^{48}$. Bir başka görüş ise bu anıtların Frig hükümdarının sarayını sembolize ettiği yönündedir. Yani bu anıtlar tanrıçayı kralın evinde göstererek Tanrıça Matar'ı Frig Devleti'ni koruyan bir tanrıça olarak ilan etmektedir. Ana Tanrıça kültünün Frigya'nın ve Frig hükümdarlık gücünün korunmasında önemli bir dinsel ritüel olduğuna ve kahramanlaştırılmış kralın bazı Matar tapınaklarında bu ritüeli paylaştığına işaret ettiğine de değinilmektedir ${ }^{49}$. Ayrıca Midas, Antik Yunan kaynaklarında tanrıçanın dinsel törenlerini kuran kişi olarak gösterilmiş ve Kybele'nin oğlu olarak ifade edilmiştir ${ }^{50}$.

Frigya Bölgesi'nde yapılan epigrafik araştırmalar, birçok yerel tanrı ve kültün aslında Anadolu'nun çok eski yerli kültlerinin Helenleşmesi sonucunda ortaya çıktığını göstermekle birlikte, yazıtlarda sıklıkla Yunan tanrılarının isimlerinin geçtiğini ancak bu isimlerle birlikte kullanılan epithetonların, çoğunlukla bu tanrılarla kastedilen yerli tanrılar olduklarını göstermektedir ${ }^{51}$. Ayrıca bölgedeki epigrafik ve ikonografik malzemeler, Helenistik ve Roma dönemlerinde özellikle farklı epithetlerle Zeus'a çok sayıda adağın olduğunu göstermektedir ${ }^{52}$. Kuzeybatı Frigya'da özellikle kırsal kesim insanları, farklı yan isimlerle anılan hava ve bereket tanrısı Zeus'a çok sayıda adak

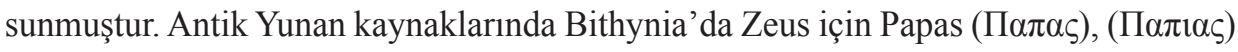
epithetinin kullanıldığ $1^{53}$ ve üstelik Papas ya da Zeus Papas'ın, Dağlık Frigya'da Yunanca yazıtlarda da geçtiği görülmektedir ${ }^{54}$. "Baba Zeus" anlamına gelen bu epithet'in Attis için de kullanıldığı bilinmektedir ${ }^{55}$. Zeus Papas'ın kült merkezi olarak Nakoleia (Seyitgazi) kabul edilmesine karşın, kuzeybatı Frigya'da da bu kült görülmektedir ${ }^{56}$. Frigya'nın yerel tanrısı olan Zeus Papas, kırsal kesimin tarıma yardımcı olan tanrıs1 işlevindedir ${ }^{57}$. Bununla birlikte birkaç Eski-Frigçe yazıtta "Baba" kelimesi ortaya çıkmaktadır ${ }^{58}$ ve bu kelimenin tıpk1 "anne" anlamında kullanılan Matar gibi ${ }^{59}$, "baba"

48 Vassileva, "PAREDROI or Once Again on the Phrygian Rock Thrones", 275.

49 Roller, "Frig Dini ve Kült Uygulamaları", 223

50 Lynn E. Roller, “The Legend of Midas," Californian Studies in Classical Antiquity 14/1 (1983), 309.

51 Nalan Eda Akyürek Şahin, Yazıdere (Seyitgazi) Zeus Kutsal Alanı ve Adak Yazıtları (İstanbul: Ege Yayınları, 2006), 3.

52 Thomas Drew-Bear ve Christian Naour, "Divinités de Phrygie," Aufstieg und Niedergang der Römischen Welt II. 18/3 (1990), 1915-2032; Stephen Mitchell, Anatolia: Land, Men and Gods in Asia Minor, 2 vols. (Oxford: Clarendon Press, 1993), vol. II, 22-24.

53 Susanne Berndt Ersöz, "In Search of a Phrygian Male Superior God”, Offizielle Religion, Lokale Kulte und Individuelle Religiosität: Akten des Religionsgeschichtlichen Symposiums, "Kleinasien und Angrenzende Gebiete vom Beginn des 2. bis zur Mitte des 1. Jahrtausends v. Chr.” (Bonn, 20- 22 Februar 2003) Alter Orient und Altes Testament 318, ed. M. Hutter ve S. Hutter Braunsar (Münster: Ugarit-Verlag 2004), 50.

54 Drew-Bear ve Naour, "Divinités de Phrygie," 2018-2022; Stephen Mitchell, Anatolia: Land, Men and Gods in Asia Minor, vol. II, 62.

55 Nuran Şahin, Zeus'un Anadolu Kültleri (İstanbul: Pera Müzesi Yayınları 2001), 145.

56 Drew Bear ve Naour, "Divinités de Phrygie", 2018-2022.

57 Drew Bear ve Naour, "Divinités de Phrygie”, 2020; Nuran Şahin, Zeus'un Anadolu Kültleri, 146.

58 Brixhe ve Lejeune, Corpus des Inscriptions Paléo-phrygiennes, nos. M-01b, G-06, G-121, G-184.

59 Roller, In Search of God the Mother. The Cult of Anatolian Cybele, 2. 
anlamına geldiği ileri sürülmektedir. ${ }^{60}$. Brixhe ve Lejeune, $b a b a$ kelimesinin büyük bir olasılıkla bir tanrıdan ziyade bir insana işaret etmesi gerektiğini belirtmektedirler ${ }^{61}$. Yazitlarda geçen bir diğer kelime ise -ata' $\mathrm{d}_{1}{ }^{62}$. "Ata" kelimesinin Anadolu ya da Hitit terimi olduğu, Hitit dilinde -atta'nın, Baba ya da Baba Tanrl için kullanıldığı belirtilirken ${ }^{63}$, Brixhe ve Drew Bear ise epigrafik ve edebi kaynaklarda işaret edilen Papas ile bağlantılı olduğunu ve bunun bir tanrı ismi olduğunu öne sürmektedirler ${ }^{64}$. Böylece Frig erkek üstün tanrısı -atanın "Baba" olduğuna işaret etmektedirler. Frigya Bölgesi Hellenize olduğunda -ata'nın genel olarak Zeus ile synkretize olduğu fakat bazı bölgelerde Yunanca şekli ile "Papas", "baba" olarak adlandırıldığı belirtilmektedirr" Özellikle Zeus'un bu kadar çok belgelenmesi, Frigya'da kökeni çok eski dönemlere inen, toprağa dayalı baskın bir ataerkil baba tanrı inancının varlığına işaret ettiği şeklinde açıklanmaktadır ${ }^{66}$. Sonuç olarak epigrafik buluntulara ve buluntuların analizlerine göre gerek basamaklı altarlarda gerekse de stellerde görülen çift idollerden birinin tanrıçayı diğerinin de Tanrıçanın paredrosunu yani ona eşlik eden tanrılardan belki de bir baba tanrıyı ifade ettiğini düşünmek yanlış olmasa gerektir.

Çift idollerin dışında, tek bir kaya kütlesi üzerinde bilinen üçlü idol örnekleri, Dağlık Frigya'da Köhnüş Vadisi'nde ${ }^{67}$ ve Yazllıkaya/Midas Kale'de ${ }^{68}$ görülmektedir (G. 6, G. 7). Midas Kale'de dik bir kaya kütlesi üzerindeki yan yana sıralanmış üç idol derin kazıma çizgi ile sınırlandırılmışlardır. Bu sınırlandırma içerisinde idollerden ikisi, tek bir gövdede iki baştan oluşmakta ve bu başlar çift sıra kazıma çizgi ve en üstte ise bu çift idolü kapsar biçimde konumlandırılmış her iki ucu volüt şeklinde biten bir sınırlandırma ile sonlanmaktadır (G. 7). Özellikle iki başın bulunduğu idolleri sınırlandıran bu volütlerin bazı örneklerde başların yanlarında omuz üzerinde kıvrıldığı görülmektedir. Başların çevresinde görülen bu detaylar, saç lüleleri olarak da yorumlandığ gibi $^{69}$, Hitit kanatlı kursu ile de ilişkilendirilerek kralların ve tanrıların imajları ile ilişkili krallara özgü bir başlık olarak da tanımlanmaktadır ${ }^{70}$. Ancak bu çift idol örneğinde, iki başı sınırlandıran çizgilerin üzerindeki detaylar, olasılıkla

60 Berndt Ersöz, "In search of a Phrygian Male Superior God", 51.

61 Brixhe ve Lejeune, Corpus des Inscriptions Paléo-phrygiennes, nos. M-01b, G-121, G-184.

62 Rodney S. Young, The Gordion Excavations, Final Reports. Vol. I, Three Great Early Tumuli (Philedelphia: Penn Press, 1981) no. MM 69, 130, 273-275; Brixhe ve Lejeune, Corpus des Inscriptions Paléo-phrygiennes, nos. G-107, W-08, W-09, W-10.

63 Berndt Ersöz, "In search of a Phrygian Male Superior God", 51.

64 Brixhe ve Drew Bear, "Trois Nouvelles Inscriptions Paleo-phrygiennes de Cepni”, 82-84.

65 Berndt Ersöz, "In Search of a Phrygian Male Superior God", 51.

66 Akyürek Şahin, Yazıdere (Seyitgazi) Zeus Kutsal Alanı ve Adak Yazıtları, 3.

67 Fahri Işıı, Doğa Ana Kubaba: Tanrıçaların Ege'de Buluşması (İstanbul: Suna-İnan Kıraç Akdeniz Medeniyetleri Araştırma Enstitüsü, 1999), 76, res. 42.

68 Tüfekçi Sivas, Eskişehir-Afyonkarahisar-Kütahya İl Sinırları İçindeki Phryg Kaya Anıtları, Lev. 135 a-b.

69 Berndt Ersöz, Phrygian Rock-Cut Shrines. Structure, Function, and Cult Practise, 58; Maya Vassileva, "Phrygian Rock-Cut Thrones, Idols And Phrygian Royal Symbolism", Thracia 18 (2009), 111; Emre Erdan,

“Frig Tipi Fibulalarda Tanrıça Sembolizmi Üzerine Bazı Düşünceler," Art-Sanat 11 (2019), 168-170.

70 Vassileva, "Phrygian Rock-Cut Thrones, Idols And Phrygian Royal Symbolism", 116-117. 
bu iki başın sembolik birlikteliğine işaret eden bir sınırlama olmalıdır. Bu idollerin $10 \mathrm{~cm}$ güneyinde aynı düzlemde bulunan idol ise tektir ve başın çevresinde hemen yanındaki ikili idol gibi bir detay yoktur. Bu durumda olasılıkla tek gövdeyi paylaşan idollerin birbiriyle eş konumdaki tanrıları, diğer idolün ise bu eş konumdaki tanrılar ile olan birlikteliği yansıttığı düşünülebilir.

Köhnüş Vadisi’ndeki kaya kütlesi üzerinde bulunan üçlü idol örneğinde ise, ortadaki idol büyük olarak yapılmıştır. Büyük idolün her iki yanında ancak bu idolle aynı hizada bulunmayan, daha altta yapılmış idoller vardır. Bu üçlü idollerde olasılıkla merkezi konumdaki idol Ana Tanrıça, yanında ona eşlik eden idoller ise tanrıçaya eşlik eden tanrılara bir işaret olabilir. Merkezde biraz daha büyük bir idol ve iki yanda daha aşağıda ve daha küçük iki idol şeması, Boğazköy heykel grubunda görülen, merkezi konumda bulunan Matar ve ona eşlik eden daha küçük boyutlu iki erkek figürünün şematize edilmiş betimini akla getirmektedir. Boğazköy grubunda, tanrıçanın yanındaki figürler, tanrıçadan oldukça küçük yapılmışlardır (G. 9).

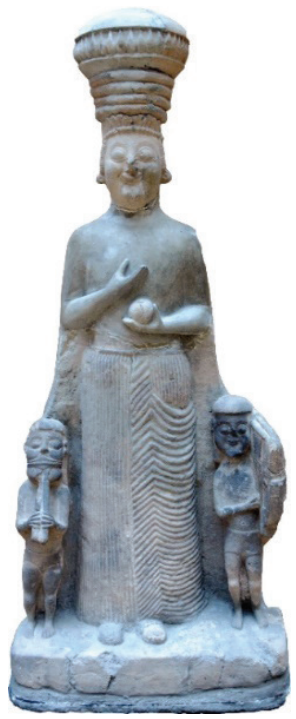

G. 9: Çorum ili, Hattuşa / Boğazköy Heykel Grubu (Anadolu Medeniyetleri Müzesi, R. Tamsü Polat, 2016)

Figürlerin küçük olarak yapılması, tanrıçanın üstünlüğünün vurgulanması ile açıklanırken bazı araştırmacılar bu figürlerin cüce veya çocuk betimi olduğunu belirtmektedir ${ }^{71}$. Bu durumda Köhnüş Vadisi’nde bulunan üçlü idol kabartması, Boğazköy grubu ile ilişkilendirilerek tanrıça ve onun yanında, onun ile eş konumda olmayan fakat ona eşlik eden ve birlikte görülen yardımcıları olarak tanımlanabilir. 
Kayalık alanda tespit edilmiş az sayıdaki üçlü idol örnekleri dışında, Nakoleia sınırlarında bulunmuş olan idol biçiminde şekillendirilmiş tüf taşı üzerindeki üç baş ve gövdenin kazıma olarak yapıldığı stel ise hem üzerindeki Eski Frigçe yazıtın içeriği hem de betim şeması açısından ilginç ve tekil bir örnektir. Steldeki başların ikisi aynı ölçüde yapılmış olup, bu başların hemen altında, ortada yapılmış olan baş ise daha küçüktür ${ }^{72}$ (G. 8). Stelde birbiri ile aynı ölçülerde yapılmış olan başların, eş konumdaki tanrıları, belki de Ana Tanrıça Matar'1 ve bir Baba tanrıyı, daha küçük olan başın ise olasılıkla daha genç bir tanrıyı sembolize ettiği belirtilmektedir ${ }^{73}$. Bu üçlü betimin şimdilik Frig ikonografisinde bilinmediği, bu betim şemasının Yunan ve Roma panteonunda görülen Kybele, Zeus ve Hermes triasını akla getirdiği üzerinde durulmaktadır ${ }^{74}$. Esasen araştırmacılar da Küçük Asya, Yunan ve Roma'da ortaya çıkan Meter'in, Zeus ve Hermes ile olan triasından oluşan birlikteliğinin köklerinin Küçük Asya Panteonu'nda aranması gerektiğini söylemektedirler ${ }^{75}$. İşte bu yeni bulunan stel, bu trianın Frig dönemindeki öncüllerine dair bir iz olarak yorumlanabilir.

\section{Tarihlendirme}

Frig idollerinin tarihlendirmesinde idollü basamaklı altarlar ve kazı çalışması yapılmış merkezlerde bulunan yarı-ikonik idoller yardımcı olmaktadır. Tarihlemeye dair uzmanların farklı yorumları bulunmaktadır. Bunun nedeni oldukça yalın bir şemada yapılan idollerin tarihlemeye yardımcı olabilecek bezeme unsurlarını barındırmayışıdır. Genel olarak idollü basamaklı altarların bulunduğu alanda ele geçen az sayıdaki seramik parçası ile basamakların gerisinde yer alan idollerin formlarından ve beş adet kaya altarında görülen ${ }^{76}$ Eski-Frigçe yazıtlardaki harf karakterinden yola çıkarak basamaklı Frig kaya altarları için farklı tarihlendirme önerileri vardır. W. M. Ramsay idollü basamaklı kaya altarlarını MÖ 1. binyıla ${ }^{77}$, Th. Bossert MÖ 6. yüzyıla, ${ }^{78} \mathrm{~K}$.

72 Büyük başlar 17,5 cm çapında, ortadaki küçük baş 10,5 cm çapındadır. Tamsü Polat, Polat ve Lubotsky, “An Idol-shaped Stele with an Old Phrygian Inscription in the Territory of Nakoleia," 54.

73 Tamsü Polat, Polat ve Lubotsky, “An Idol-shaped Stele with an Old Phrygian Inscription in the Territory of Nakoleia," 56.

74 Tamsü Polat, Polat ve Lubotsky, “An Idol-shaped Stele with an Old Phrygian Inscription in the Territory of Nakoleia," 55.

75 Feriştah Soykal Alanyalı, “Ana Tanrıça Kültünde Çobanlar ve Çoban Tanrılar,” Çoban Kitabı, ed. Emine Gürsoy Naskali (İstanbul: Kitabevi Yayınları, 2011), 149-151.

76 Midas Kale'deki altarlar için bk. Brixhe ve Lejeune Corpus des Inscriptions Paléo-phrygiennes, 25-26, pl. XII; Haspels, The Highlands of Phrygia. Sites and Monuments, 291-292, no.7, 9, fig. 599, 600; Brixhe ve Lejeune, Corpus des Inscriptions Paléo-phrygiennes, 19-21, M- 04, pl. VIII-2, IX, 3; Menekşe Kayalıklarındaki altar için bk. Claude Brixhe ve Taciser Sivas, "Dédicace Paleo-Phrygienne Inédite (Menekșekaya/ Demirli)," Kadmos 41(2003), 103-116; Kalehisar Tepesi'ndeki altar için bk. Brixhe ve Lejeune, Corpus des Inscriptions Paléo-phrygiennes, 242-243, no. P-06, lev. 124-125.

77 William M. Ramsay, “A Study of Phrygian Art II,” Journal of Hellenistic Studies X (1889), 167-168.

78 Theodor Helmuth Bossert, Altanatolien: Kunst und Handwerk in Kleinasien von den Anfängen bis zum völligen Aufgehen in der griechischen Kultur (Berlin: E. Wesmuth, 1942), 1101 
Bittel $^{79}$ ve M. J. Mellink MÖ 8. yüzyıla tarihlemiştirir ${ }^{80}$. E. Akurgal ise idol şeklindeki betimlerden yola çıarak Matar'ın Frig döneminde ikonografik olarak yalnız betimlendiğini, Roma döneminde tanrıçanın bir eşle birlikte gösterilmesinden dolayı da çift idollerin geç dönemlerde ortaya çıktığını belirtmektedir ${ }^{81}$. Ancak idollerin formlarına göre bir tarihleme yapmak doğru bir sonuca ulaştıramayacağ gibi, her idol tipinin bir arada eş zamanlı olarak kullanıldığı özellikle yan yan yapılmış altarlarda, basamakların gerisindeki farklı tiplerdeki idollerden anlaşılmaktadır ${ }^{82}$.

Kazı çalışmalarının yapıldığ 1 yerleşimlerde tespit edilmiş bir grup yarı-ikonik idol de Frig idollerinin tarihlendirilmesine katk1 sağlamaktadır. Örneğin Gordion' da ${ }^{83}$ MÖ 7. yüzyılın 3. çeyreğine tarihlenen Tümülüs $\mathrm{B}^{\prime} \mathrm{de}^{84}$ bulunan yarı-ikonik idoller, dolgu tabakasında bulunduğundan tümülüsün yapımı öncesine, yani yaklaşık olarak MÖ geç 8. yüzyıl-erken 7. yüzyılllara tarihlendirilmektedir ${ }^{85}$. Bunun dışında Nakoleia s1nırlarında bulunan stel ise stelin formu ve stel üzerindeki Eski Frigçe yazıttaki harf karakterinden Orta Frig dönemine (MÖ 800-550) ${ }^{86}$, Boğazköy'de Frig evinin ön odasında in situ konumda bulunmuş, kireç taşından yapılmış idollü minyatür altar MÖ 8. yüzyıl ortası-MÖ 7. yüzyıla ${ }^{87}$, Kerkenes Dağ' da Saray kompleksi girişinde, Kapodokya Kapısı'ndaki idoller, MÖ 6. yüzyıl ortasına ${ }^{88}$, Ovaören/Yassıhöyük idolü Orta Frig dönemine (MÖ 800-550) tarihlendirilmiştir ${ }^{89}$. Bu örneklerin yanı sıra Gordion'da MM, P ve W tümülüslerinde yapılan kazılarda ortaya çıkartılan ve MÖ 8. yüzyıla tarihlendirilen çok sayıdaki ahşap eser arasında bulunan servis stantlarının yüzeylerinde, motiflerin ortasına, merkezi konuma yerleştirilmiş desenler de Frig Tanrıçası

79 Kurt Bittel, Kleinasiatische Studien, Istanbuler Mitteilungen, Heft 5 (İstanbul: Deutsches Archäologisches Institut, 1942), 83.

80 Mellink, "Temples and High Places in Phrygia," 97.

81 Ekrem Akurgal, Phrygische Kunst (Ankara: Ankara Üniversitesi, 1955), 97.

82 Kütahya ili, Fındık Asarkale yerleşimindeki altarlar genellikle ikili, üçlü ve dörtlü gruplar halinde yan yana yapılmıştır. Bu altarlarda farklı tipte idol örnekleri görülür. Tamsü, "Observations on the Phrygian Rock-Cut Altars," 440-441.

83 DeVries, "The Gordion Excavation Seasons of 1969-1973 and Subsequent Research," fig. 36; Kohler, The Gordion Excavations 1950-1973 Final Reports. The Lesser Phrygian Tumuli, 13-14, 20-21, nos. Tüm B 17, pl. 11 A-B.

84 Ellen L. Kohler, The Gordion Excavations 1950-1973 Final Reports. The Lesser Phrygian Tumuli. Part 1. The Inhumations. Vol. II (Philadelphia: University of Pennsylvania, 1995), 20-23, nos. Tüm B 33, Tüm B 34, Tüm B, 35, pl. 11A-B, 12 H-M.

85 Kohler, The Gordion Excavations 1950-1973 Final Reports. The Lesser Phrygian Tumuli, 20-23.

86 Tamsü Polat, Polat ve Lubotsky, "An Idol-shaped Stele with an Old Phrygian Inscription in the Territory of Nakoleia," 58.

87 Peter Neve, "Bericht über die Ausgrabungen der Deutschen Boğazköy Expedition im Jahre 1969," Türk Arkeoloji Dergisi 18/2 (1970), 156, fig. 9a-d; Naumann, Die Ikonographie der Kybele in der Phrygischen und der Griechischen Kunst, 94-95; Prayon, Phrygische Plastik: die Früheisenzeitlische Bildkunst ZentralAnatoliens und ihre Beizehungen zu Griechenland und zum Alten Orient, 169-171.

88 Summers ve Summers, "Kerkenes Dăg," 174.

89 Akçay, "Ovaören-Yassıhöyük'den Bir Yarı İkonik İdol," 53, res. 5. 
Matar'ın soyut yansımaları olarak kabul edilmektedir ${ }^{90}$. Ahşap eserlerdeki tanrıçanın sembolik betimlerinin dişında Gordion'da Erken Frig dönemine (MÖ 950/900-800) tarihlenen Megaron 2 olarak adlandırılan anıtsal yapının duvarında kullanılan taş blok üzerinde idollü bir altarın basit çizimi bulunmuştur ${ }^{91}$. Bu çizimler de idol kavramı ile birlikte basamaklı idollü altarların ${ }^{22}$ Erken Frig döneminden itibaren varlığına dair önemli bir kanittır.

\section{Sonuç}

Ana Tanrıça Matar'ın Frig dinindeki etkin ve baskın karakteri hem bir grup kaya fasadında ve stellerde nişlerin ortasına kabartma olarak yansıyan insan suretindeki tasvirleri hem de Eski Frigçe yazıtlar ile kanıtlanmaktadır. Frig kültürü ile öncülü olan Hitit ve çağdaşı olan Geç Hitit geleneği arasında, dinsel simgeler ve doğaya olan bağlılık gibi benzerliklerin yanı sıra özellikle Ana Tanrıça Matar'ın Geç Hitit Tanrıçası ile betim açısından benzer özelliklere sahip olduğu görülmektedir. Tüm bu benzerliklerin yanında gerek Hitit gerekse Geç Hitit panteonunda görülen ikonografik tasvirler ve yazılı metinler, her iki kültürde de hem tanrı hem de tanrıçaların varlığını göstermektedir. Bu iki kültürdeki benzer yönlerin bulunuşu, Ana Tanrıça’nın neredeyse insan görünümünde tek başına varlık gösterdiği Frig dünyasında, Matar'ın yanında başka tanrı ya da tanrıçaların tapınım görüp görmediğine dair soruları beraberinde getirmektedir. Öncül ve çağdaş kültürlerin geniş panteonları bu soruyu sormada etkin bir rol oynamaktadır. Frig kültürü yayılım sahası içinde sayıca yoğun denilebilecek nitelikte tespit edilen şematize edilmiş soyut tasvirler olarak da nitelendirilen çift ya da çoklu idoller de bu soruların sorulmasına ve bazı cevapların aranmasına neden olan buluntu grubudur.

Kayalık alanlarda, kaya yüzeyine ve basamaklı kaya altarlarına, basamakların gerisindeki ana kayaya kabartma olarak yapılanlar ile stel biçimli taş bloklar üzerine kazıma şeklinde yapılan çift ya da çoklu idol örnekleri, epigrafik buluntuların analizleri ile tanrıça ve onunla birlikte tapınım gören paredrosunu, yani ona eşlik eden ve şimdilik adını bilmediğimiz bir Baba Tanrı'yı ve beraberindeki tanrıları betimlediğine dair önemli bilgiler sunmaktadır. Sonuç olarak Frig idolleri, tanrıların betimleri, imajları (yazıtlarda geçen -iman?) ve onların epifanisi (tezahürü) olarak yorumlanmalıdır.

90 Elizabeth Simpson ve Krysia Spirydowicz, Gordion Wooden Furniture (Gordion Ahşap Eserler): The Study, Conservation and Restruction of the Furniture and Wooden Objects from Gordion, 1981-1998 (Ankara: Anadolu Medeniyetleri Müzesini Koruma ve Yaşatma Derneği: 1999), 7-8; Elizabeth Simpson, "Gordion Mobilya ve Ahşap Eserleri”, ed. Taciser Tüfekçi Sivas ve Hakan Sivas (İstanbul: Yapı Kredi Yayınları, 2012), $343,349$.

91 Prayon, Phrygische Plastik: die Früheisenzeitlische Bildkunst Zentral-Anatoliens und ihre Beizehungen zu Griechenland und zum Alten Orient, 174, fig. 27a; Lynn E. Roller, The Incised Drawings from Early Phrygian Gordion, Gordion Special Studies 4, Museum Monograph 130 (Philedelphia: University of Pennsylvania Museum of Archaeology and Anthropology, 2009), 29-32.

92 Tamsü Polat, "Yeni Buluntular Işı̆̆ında Phryg Kaya Altarları ve Bir Tipoloji Önerisi”, 210. 
Genellikle doğu yöne, yani güneşin doğduğu yöne doğru bakan kayalıklarda yap1lan, şimdilik kimlikleri belirsiz (?) olan idollerin bulunduğu ve konumlandığı alanlar, yüksek kayalık platolar, su kenarları ile akarsuların suladığı bereketli ovalara doğru bakan alanlar, yerleşimlerin girişleri ${ }^{93}$, yol güzergâhları, tümülüsler ve nekropollerdir.

İdollerin buluntu konumları, kimlikleri aslında gizemli olan bu betimlerin barındırdığı tanrısal gücün ya da güçlerin niteliklerini anlamamıza yardımcı olmaktadır. Uçsuz bucaksız doğada var olma mücadelesi veren halkın korunması, yaşamın devamlılığında tarıma bağlı ekonomide ihtiyaç duyulan bolluğun ve bereketin sağlanması, ölüm sonrasında da sonsuz koruyuculuğun devamı, bu ilahi güç ya da güçlerin nitelikleri olarak görülebilir.

Hakem Değerlendirmesi: Dış bağımsız.

Çıkar Çatışması: Yazar çıkar çatışması bildirmemiştir.

Finansal Destek: Yazar bu çalışma için finansal destek almadığını beyan etmiştir.

Peer-review: Externally peer-reviewed.

Conflict of Interest: The author has no conflict of interest to declare.

Grant Support: The author declared that this study has received no financial support.

\section{Kaynakça/References}

Akçay, Atakan. “Ovaören-Yassıhöyük'den Bir Yarı İkonik İdol.” Arkeoloji ve Sanat 149 (2015): 47-54. Akurgal, Ekrem. Phrygische Kunst. Ankara: Ankara Üniversitesi, 1955.

Akurgal, Ekrem. Die Kunst Anatoliens von Homer bis Alexander. Berlin: Gruyter, 1961.

Akyürek Şahin, Nalan Eda. Yazıdere (Seyitgazi) Zeus Kutsal Alanı ve Adak Yazıtları. İstanbul: Ege Yayınları, 2006.

Barnett, Richard David. "Phrygia and The Peoples of Anatolia in The Iron Age." The Cambridge Ancient History II (1967): 1-32.

Berndt Ersöz, Susanne. "In Search of a Phrygian Male Superior God." Offizielle Religion, Lokale Kulte und Individuelle Religiosität: Akten des Religionsgeschichtlichen Symposiums "Kleinasien und Angrenzende Gebiete vom Beginn des 2. bis zur Mitte des 1. Jahrtausends v. Chr." (Bonn, 20- 22. Februar 2003, Alter Orient und Altes Testament 318). Ed. Manfred Hutter ve Sylvia Hutter Braunsar. Münster: Ugarit-Verlag, 2004, 47-56.

Berndt Ersöz, Susanne. Phrygian Rock-Cut Shrines. Structure, Function, and Cult Practise. LeidenBoston: Brill, 2006.

Bittel, Kurt. Kleinasiatische Studien, Istanbuler Mitteilungen, Heft 5, İstanbul: Deutsches Archäologisches Institut, 1942.

Bittel, Kurt. "Untersuchungen auf Büyükkale.” Mitteilungen der Deutschen Orient Gesellschaft 91 (1958): 57-72.

93 Yerleşim girişlerinde bulunan idollerin bilinen en anıtsal örnekleri, Kerkenes Dağ yerleşiminin anıtsal girişindedir. İdollerin yerleşimin girişindeki konumlarının, yöneticilere bir meşruiyet ve bir kutsal koruma kazandıran güçlü görsel imgeler olarak açıklanmaktadır. Summers ve Summers, "Kerkenes Dağ," Frigler, Midas'ın Ülkesinde, Anitların Gölgesinde, 176. 
Bittel, Kurt. "Phrygisches Kultbild aus Bogazköy.” Antike Plastik II (1963): 7-21.

Bittel, Kurt. Hattusha. The Captal of Hittites. New York: Oxford University Press, 1970.

Boehmer, Rainer Michael. Die Kleinfunde von Boğazköy: Aus den Grabungskampagnen, 19311939 und 1952-1969, Wissenscaftliche Veröffentlichung der Deutschen Orient-Gesellschaft 87, Boğazköy-Hattuša 7. Berlin: Mann, 1972.

Bossert, Theodor Helmuth. Altanatolien: Kunst und Handwerk in Kleinasien von den Anfängen Bis Zum Völligen Aufgehen In Der Griechischen Kultur. Berlin: E. Wesmuth, 1942.

Bøgh, Birgitte. “The Phrygian Background of Kybele.” Numen 54/3 (2007): 304-339.

Brixhe Claude ve Thomas Drew Bear. "Trois Nouvelles Inscriptions Paleo-phrygiennes de Cepni." Kadmos 21 (1982): 64-87.

Brixhe, Claude ve Michel Lejeune. Corpus des Inscriptions Paléo-phrygiennes. 2 vols. Paris: Éditions Recherche sur les Civilisations, 1984.

Brixhe Claude ve Taciser Sivas. "Dédicace Paleo-Phrygienne Inédite (Menekşekaya/Demirli)," Kadmos 41 (2003): 103-116.

Buluç, Sevim. "The Architectural Use of the Animal and Kybele Reliefs Found in Ankara and Its Vicinity." Source: Notes in the History of Art vol.7, 3/4 (1988): 16-23.

DeVries, Keith. "The Gordion Excavation Seasons of 1969-1973 and Subsequent Research." American Journal of Aarchaeology 94 (1990): 371-406.

Diakonoff Igor M. ve Neroznak, Vladimir Petrovich. Phrygian. New York: Caravan Books, 1985.

Drew Bear, Thomas ve Christian Naour. "Divinités de Phrygie.” Aufstieg und Niedergang der römischen Welt II. 18/3 (1990): 1907-2044.

Drews, Robert. "Myths of Midas and the Phrygian Migration from Europe.” Klio 75 (1993): 9-26.

Erdan, Emre. Frig Kültürü ve Uygarlığı. İstanbul: Arkeoloji ve Sanat Yayınları, 2018.

Erdan, Emre. "Frig Tipi Fibulalarda Tanrıça Sembolizmi Üzerine Bazı Düşünceler." Art-Sanat 11 (Ocak 2019): 163-185.

Genz, Hermann. "Thoughts on the Origin of the Iron Age Pottery Traditions in Central Anatolia." Ed. Altan Çilingiroğlu ve Gareth Darbyshire. Anatolian Iron Ages 5, Proceedings of the Fifth Anatolian Iron Ages Colloquium Held at Van, 6-10 August 2001. Ankara: British Institute at Ankara, 2005, 75-84.

Gündoğan Aydıngün, Şengül. "Yerleşik Hayat Öncesi: Yaratan Beden.” Tunç Çağı'nın Gizemli Kadınları. İstanbul: Yapı Kredi Yayınları, 2005, 11-28.

Haspels, Caroline Henriette Emilie. Phrygie, Exploration Archeologique III, La Cite de Midas, Ceramique et Trouvailles Diverses. Paris: E. De Boccard, 1951.

Haspels, Caroline Henriette Emilie. The Highlands of Phrygia. Sites and Monuments. 2 vols. Princeton: The University Press, 1971.

Herodotos. Herodot Tarihi. Çev. Müntekim Ökmen. İstanbul: Remzi Kitabevi, 1991.

Işık, Fahri. Doğa Ana Kubaba: Tanrıçaların Ege'de Buluşması. İstanbul: Suna-İnan Kıraç Akdeniz Medeniyetleri Araştırma Enstitüsü, 1999.

Işık, Fahri. Uygarlık Anadolu'da Doğdu. İstanbul: Ege Yayınları, 2012.

"Idolon”. Oxford Latin Dictionary. Ed. G. M. Lee. Oxford: the Clarendon Press, 1968, 820.

Liddell, Henry George ve Robert Scott. "Eidolon”. A Greek-English Lexicon. New York: Oxford University Press, 1996, 483. 
Mellink, Machteld J. "Temples and High Places in Phrygia." Tempels and High places in Biblical Times. Proceedings of the Colloquium in Honor of the Centennial of Hebrew Union CollegeJewish Institute of Religion, Jerusalem, 14-16 March, 1977. Ed. Avraham Brian. Jerusalem: Nelson Glueck School of Biblical Archaeology of Hebrew Union College-Jewish Institute of Religion, 1981, 96-104.

Mellink, Machteld J. “Midas-Stadt.” Reallexikon der Assyriologie 8 (1993): 153-156.

Metin, Mustafa ve Mehmet Akalın. "Frigya'da Bulunan İkiz İdol.” Anadolu Medeniyetleri Müzesi

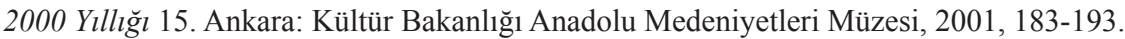

Mitchell, Stephen. Anatolia: Land, Men and Gods in Asia Minor. 2 vols. Oxford: Clarendon Press, 1993.

Naumann, Friederike. Die Ikonographie der Kybele in der Phrygischen und der Griechischen Kunst. Istanbuler Mitteilungen, Suppl. 28. Tübingen: Ernst Wasmuth 1983.

Neve, Peter. "Bericht Über Die Ausgrabungen Der Deutschen Boğazköy Expedition Im Jahre 1969." Türk Arkeoloji Dergisi 18/2 (1970): 151-167.

Olshausen, Eckart. "Phryges, Phrygia." Der Neue Pauly. Enzyklopädie der Antike, Band IX. Stuttgart: Verlag J.B. Metzler, 1996, 965-967.

Plinius. Naturalis Historia, Vol. 5. Çev. H. Rackham. (The Loeb Classical Library) London: New York, 1947.

Polat, Yusuf. "Yazılıkaya/Midas Vadisi Araştırmalarında Bulunan Bir Kaya İdolü.” Colloquium Anatolicum 18 (2019): 139-154.

Prayon, Friedhelm. Phrygische Plastik: die Früheisenzeitlische Bildkunst Zentral-Anatoliens und ihre Beizehungen zu Griechenland und zum Alten Orient. Tübingen: E. Wesmut, 1987.

Ramsay, William Mitchell. "A Study of Phrygian Art II.” Journal of Hellenistic Studies X (1889): 147-189.

Renfrew, Collin ve Paul Bahn. Arkeoloji; Kuramlar, Yöntemler ve Uygulama. İstanbul: Homer Kitabevi, 2017.

Roller, Lynn E. "The Legend of Midas." Californian Studies in Classical Antiquity 14/1 (1983): 299-313.

Roller, Lynn E. “Attis on Greek Votive Monuments: Greek God or Phrygian?” Hesperia 63/2 (1994): 245-262.

Roller, Lynn E. In Search of God the Mother. The Cult of Anatolian Cybele. London: Berkeley Los Angeles, 1999.

Roller, Lynn E. The Incised Drawings from Early Phrygian Gordion, Gordion Special Studies 4, Museum Monograph 130. Philedelphia: University of Pennsylvania Museum of Archaeology and Anthropology, 2009.

Roller, Lynn E. “Frig Dini ve Kült Uygulamaları”, Frigler, Midas'in Ülkesinde, Anıtların Gölgesinde. Ed. Taciser Tüfekçi Sivas ve Hakan Sivas. İstanbul: Yapı Kredi Yayınları, 2012, 202-231.

Roller, Lynn E. “Frig Dini ve Kült Uygulamaları”, Friglerin Gizemli Uygarlığı. İstanbul: Yapı Kredi Yayınlar1, 2007, 141-147.

Simpson, Elizabeth ve Spirydowicz Krysia. Gordion Wooden Furniture (Gordion Ahşap Eserler): The Study, Conservation and Restruction of the Furniture and Wooden Objects from Gordion, 1981-1998. Ankara: Anadolu Medeniyetleri Müzesini Koruma ve Yaşatma Derneği: 1999. 
Simpson, Elizabeth. “Gordion Mobilya ve Ahşap Eserleri”. Frigler, Midas'ın Ülkesinde, Anitların Gölgesinde. Ed. Taciser Tüfekçi Sivas ve Hakan Sivas. İstanbul: Yap1 Kredi Yayınları, 2012: 334-356.

Sivas, Taciser. "Eskişehir-Kütahya-Afyonkarahisar İlleri 2001 Yılı Yüzey Araştırması." Araştırma Sonuçları Toplantısı 20/2 (2003): 285-298.

Soykal Alanyalı, Feriştah. “Ana Tanrıça Kültünde Çobanlar ve Çoban Tanrılar.” Çoban Kitabı. Ed. Emine Gürsoy Naskali. İstanbul: Kitabevi Yayınları, 2011, 145-158.

Strabon. Coğrafya Anadolu: Kitap: XII-XIII-XIV. Çev. Adnan Pekman. İstanbul: Arkeoloji ve Sanat Yayınları, 1987.

Summers, Geoffrey ve Françoise Summers. "Kerkenes Dağı Projesi 2003.” Kazı Sonuçları Toplantısı 26/1 (2005): 97-110.

Summers, Geoffrey D. ve Françoise Summers. "Kerkenes 2009.” Kazı Sonuçları Toplantısı 32/1 (2011): 381-402.

Summers, Geoffrey D. ve Françoise Summers. "Kerkenes Dağ." Frigler, Midas'ın Ülkesinde, Anıtların Gölgesinde. Ed. Taciser Tüfekçi Sivas ve Hakan Sivas. İstanbul: Yapı Kredi Yayınları, 2012, 162-183.

Summers, Geoffrey D. "Phrygians East of the Red River: Phrygianisation, Migration and Desertion." Anatolian Studies 68, (2018): 99-118.

Şahin, Nuran. Zeus'un Anadolu Kültleri. İstanbul: Pera Müzesi Yayınları, 2001.

Tamsü, Rahşan. "Observations On The Phrygian Rock-Cut Altars." SOMA 2005 Proceedings of the IX Symposium on Mediterranean Archaeology, Chieti (Italy), 24-26 February 2005, Bar International Series, Vol. 1739 (2008): 439-445.

Tamsü Polat, Rahşan. "Yeni Buluntular Işı̆̆ında Phryg Kaya Altarları ve Bir Tipoloji Önerisi." Anadolu Üniversitesi Sosyal Bilimler Dergisi 10/1 (2010): 203-222.

Tamsü Polat, Rahşan, Yusuf Polat ve Alexander Lubotsky. "An Idol-shaped Stele with an Old Phrygian Inscription in the Territory of Nakoleia." Gephyra 19 (2020): 45-67.

Tüfekçi Sivas, Taciser. Eskişehir-Afyonkarahisar-Kütahya İl Sinırları İçindeki Phryg Kaya Anıtları. Eskişehir: Anadolu Üniversitesi Yayınları, 1999.

Tüfekçi Sivas, Taciser ve Hakan Sivas, "Eskişehir-Kütahya-Afyon İlleri Yüzey Araştırmas1 Arkeolojik Envanter Raporu.” Tüba-Kültür Envanteri Dergisi 1 (2003): 2-32.

Umurtak, Gülsün. “İdol.” Eczacıbaşı Sanat Ansiklopedisi 2. İstanbul: Yapı Endüstri Merkezi Yayınları, 1997, 834.

Vassileva, Maya. "PAREDROI or Once Again on the Phrygian Rock Thrones." Thracia 11, (1995): 265-276.

Vassileva, Maya. "Phrygian Rock-Cut Thrones, Idols And Phrygian Royal Symbolism." Thracia 18 (2009): 111-124.

Vikela, Evgenia. "Bemerkungen zu Ikonographie und Bildtypologie der Meter-Kybelereliefs." Mitteilungen des Deutschen Archäologischen Instituts. Athenische Abteilung 116 (2001): 67-123.

Von der Osten, Hans Henning. Explorations in Central Anatolia, Season of 1926. Chicago: The University of Chicago, 1929.

Young, Rodney S. “Gordion-1950.” University Museum Bulletin 16/1 (1951): 2-19.

Young, Rodney S. “Doodling at Gordion.” Archeology 22 (1968): 270-275.

Young, Rodney S. The Gordion Excavations, Final Reports. Vol. I, Three Great Early Tumuli. Philedelphia: Penn Press, 1981. 
